\title{
Augmented Attributions: The Role of Perceived Effort in the Formation of Consumer Motive Attributions: An Abstract
}

\author{
Ryan Langan and Anand Kumar
}

\begin{abstract}
In recent years, the nature of corporate giving has begun to change. Corporate philanthropy, whereby a corporation donates a portion of its resources to a societal cause, has become more focused and strategic in its execution (Gautier and Pache 2013). To that end, there remains the need for a deeper understanding of the underlying processes that drive returns from CSR-related activities. Prior research has demonstrated that for CSR initiatives to be successful, consumers must believe the company is support a cause for the right reasons.

In this research, we submit that perceived effort plays an instrumental and previously undelineated role in the formation of consumers' motive attributions. Guided by attribution theory and the augmentation principle, three studies are put forth to demonstrate how the type, nature, and source of giving influence consumers' perception of effort and, ultimately, their evaluation of the firm.

Using data collected from online survey panels, we find that donations of time and money differentially influence consumers' attitude toward the firm via serial mediation. Specifically, corporate donations of time (compared to money) lead to higher levels of perceived effort, which in turn induces more altruistic motive attributions and, ultimately, a more positive attitude toward the firm. We also find that the effect of donation type on perceived effort is moderated by consumers' perception of the relative cost of the donation to the firm, whereby donations of equivalent value from a firm with fewer resources are perceived to be more effortful. Collectively, our model depicting moderated serial mediation provides insights into the process through which consumers form motive attributions in the context of corporate giving.
\end{abstract}

References Available Upon Request

\author{
R. Langan $(\bowtie)$ \\ University of San Francisco, San Francisco, CA, USA \\ e-mail: rjlangan@usfca.edu
}

\author{
A. Kumar \\ University of South Florida, Tampa, FL, USA \\ e-mail: akumar@usf.edu
}

